\title{
Additives and Protein-DNA Combinations Modulate the Humoral Immune Response Elicited by a Hepatitis C Virus Core-encoding Plasmid in Mice
}

\author{
Liz Alvarez-Lajonchere/+,Santiago Dueñas-Carrera, Ariel Viña, Thelvia Ramos*, \\ Dagmara Pichardo,Juan Morales
}

HCV Department, Vaccine Division, Centro de Ingeniería Genética y Biotecnología *Centro Nacional de Genética Médica, Casilla Postal 6162, Havana City, Cuba

Humoral and cellular immune responses are currently induced against hepatitis $C$ virus (HCV) core following vaccination with core-encoding plasmids. However, the anti-core antibody response is frequently weak or transient. In this paper, we evaluated the effect of different additives and DNA-protein combinations on the anti-core antibody response. BALB/c mice were intramuscularly injected with an expression plasmid (pIDKCo), encoding a C-terminal truncated variant of the HCV core protein, alone or combined with $\mathrm{CaCl}_{2}, P E G 6000$, Freund's adjuvant, sonicated calf thymus DNA and a recombinant core protein (Co.120). Mixture of pIDKCo with PEG 6000 and Freund's adjuvant accelerated the development of the anti-core Ab response. Combination with PEG 6000 also induced a bias to IgG2a subclass predominance among anti-core antibodies. The kinetics, IgG2a/IgG1 ratio and epitope specificity of the anti-core antibody response elicited by Co.120 alone or combined with pIDKCo was different regarding that induced by the pIDKCo alone. Our data indicate that the antibody response induced following DNA immunization can be modified by formulation strategies.

Key words: hepatitis C virus - DNA immunization - core

It is now well established that injection of plasmid DNA through a wide range of routes induces both humoral and cellular immune responses against the encoded proteins in several hosts. Moreover, immune responses induced by DNA immunization have lead to protection against various viral, bacterial and parasitic pathogens (Donnelly et al. 1997). However, immune responses generated by this methodology against several antigens remain insufficient (Hasan et al. 1999). While the majority of the experiments conducted to date have used phosphate buffered saline $\mathrm{pH} 7.5$ (PBS) or saline as a diluent for the injected DNA, a great deal of effort is now being applied to the development of delivery vehicles and adjuvants. Such reagents may increase the uptake of DNA, reduce the necessary dose for immunization and enhance subsequent immune responses. Some systems currently under investigation are cationic liposomes (Gregoriadis et al. 1997), immunostimulatory oligonucleotide sequences (Klinman et al. 1997), cytokines (Chow et al. 1997) and monophosphoryl lipid A (Sasaki et al. 1998).

In this paper, different formulations were investigated to modulate the antibody response generated by a DNA vaccine. We studied the humoral immune response elicited by vaccination with a plasmid encoding a truncated variant of the hepatitis $\mathrm{C}$ virus (HCV) core protein. Several $\mathrm{B}$ cell and cytotoxic T-lymphocyte determinants within the HCV core protein have been characterized (Walker 1996, Jackson et al. 1997). Moreover, of the various regions of $\mathrm{HCV}$, antibodies against the core protein are often the first

\footnotetext{
+Corresponding author. Fax: +53-7-214764.

E-mail: juan.morales@cigb.edu.cu

Received 20 February 2001

Accepted 10 October 2001
}

to appear during HCV natural infection (Okamoto et al. 1992). However, plasmid expressing the HCV nucleocapsid alone often elicited strong cellular but weak and/or transient humoral immunity (Lagging et al. 1995, Chen et al. 1995). Consequently, the HCV core antigen is a good model for investigations about the modulation of antibody response generated following DNA immunization. We particularly investigated different additives to facilitate the plasmid stability and uptake by the cells. Use of a classical adjuvant like Freund and the combination of plasmid DNA with a recombinant core protein were also evaluated to obtain an improved anti-core antibody response.

\section{MATERIALS AND METHODS}

Co. 120 protein - Recombinant Co. 120 is an Escherichia coli-derived protein containing the first 120 amino acids of HCV viral polyprotein. It was purified by a combination of washed pellet procedures and gel filtration chromatography as previously described (Dueñas-Carrera et al. 1999). Briefly, recombinant protein was expressed in BL21 (DE3) E. coli cells. For purification, expressing cells were disrupted with French press (Braund, 1,500 kg/cm ${ }^{2}$ ) at $1 \mathrm{~g} / \mathrm{ml}$ in $10 \mathrm{mM}$ Tris $\mathrm{HCl}, 6 \mathrm{mM}$ EDTA, $\mathrm{pH} 8$. The insoluble fraction of cell lysate was washed with $0.5 \mathrm{M}$ urea, $1 \%$ Triton $\mathrm{X}-100,10 \mathrm{mMEDTA}, 300 \mathrm{mM} \mathrm{NaCl}, 10 \mathrm{mM}$ 2-mercaptoethanol, $10 \mathrm{mM}$ Tris $\mathrm{HCl} \mathrm{pH} 8$ buffer. Co. 120 protein was solubilized by increasing the concentration of the urea up to $2 \mathrm{M}$. The supernatant was desalted on a Sephadex-G25 column equilibrated with carbonate buffer, $\mathrm{pH}$ 10.6. Desalting by gel filtration rendered soluble Co.120 protein at $95 \%$ of purity.

Human sera - Human sera were obtained from blood donors and chronic patients and previously screened for the presence of anti-HCV antibodies by UMELISA HCV from Centro de Inmunoensayo (La Habana, Cuba). The anti-HCV positive sera were also confirmed by Ortho HCV 2.0 ELISA (Ortho Diagnostic Systems, Raritan, NJ).

Plasmids - pAEC-K6: expression vector that contains the human cytomegalovirus immediate early promoter, sim- 
ian virus 40 terminator and polyadenylation sequences, a bacterial replication origin from pUC and a kanamycin resistant gene as selection marker. pIDKCo: an expression plasmid generated by inserting a 528 nucleotide DNA fragment, coding for the first 176 aa of the HCV core protein, into the compatible sites of the pAEC-K6 (Dueñas-Carrera et al. 2000).

E. coli strain XL-1 Blue [(F', proAB, lacI $\left.{ }^{\mathrm{q}} \Delta \mathrm{ZM} 15, \mathrm{Tn} 10\right)$, endA, hsdR17, supE, thi-1, recA1, gyrA96, relA1, lac.] was transformed with pIDKCo and pAEC-K6 plasmids. Cells were grown under selective pressure with $50 \mathrm{mg} / \mathrm{l} \mathrm{kanamy-}$ cin. Plasmid DNA was subsequently purified as previously described (Horn et al. 1995).

Animals and immunization schedule - BALB/c female mice of 6 to 8 weeks old (18-20 g of weight) were purchased from CENPALAB (Ciudad de la Habana, Cuba) and hosted in appropriated animal care facilities during the experimental period. The animals were handed following the international guidelines required for experimentation with animals. Mice were injected at 0 and 3 weeks, in the quadriceps muscle, with $100 \mu \mathrm{l}$ of different immunogens. Blood samples were collected from the retro-orbital sinus at 0,5 , and 14 weeks after the primary immunization. The mice were euthanized after the final blood samples were taken. The study included 10 groups of 5 mice each. The groups were conformed as follows: group 1 (pAEC-K6) was injected with a mock DNA (pAEC-K6 plasmid). The second group (Co.120-pIDKCo) received pIDKCo combined with the protein Co.120. Both components were blended and stirred overnight. This mixture was centrifuged for $15 \mathrm{~min}$ at 3,000 $\mathrm{xg}$ and the supernatant was given as immunogen. The third (Co.120) and fourth (pIDKCo) groups received the Co.120 protein and the pIDKCo alone, respectively. Groups $5\left(\mathrm{CaCl}_{2}\right), 6$ (PEG 6000), 7 (Freund's) and 8 (sCTDNA) were immunized with pIDKCo combined with 100 $\mathrm{mM} \mathrm{CaCl}_{2}$ (Merck, Darmstadt, Germany), 1\% PEG 6000 (Merck, Darmstadt, Germany), Freund's adjuvant (Sigma, St Louis, USA) and $100 \mu \mathrm{g}$ of sonicated calf thymus DNA (sCT-DNA) (Promega, Madison, USA), respectively. Group 9 (pIDKCo/Co.120) was primed with pIDKCo and boosted with Co.120. The last group (Co.120/pIDKCo) was primed with Co.120 and boosted with pIDKCo. Plasmids were administered at $1 \mu \mathrm{g} / \mu \mathrm{l}$ and Co.120 protein at $0.1 \mu \mathrm{g} / \mu \mathrm{l}$ in PBS.

Enzyme-linked immunosorbent assay (ELISA) - To detect murine anti-core antibodies, 96-well microtiter plates (Costar, Cambridge, MA, USA) were coated with $100 \mu \mathrm{l}$ of Co. $120(10 \mu \mathrm{g} / \mathrm{ml})$ diluted in coating buffer $(50 \mathrm{mM}$ carbonate buffer, $\mathrm{pH} 9.6)$ overnight at $4^{\circ} \mathrm{C}$. The wells were washed three times with $0.05 \%$ Tween 20 in PBS (PBST) and blocked with $200 \mu \mathrm{l}$ of PBST containing 1\% skimmed milk (Oxoid, Basingstoke, Hampshire, England) for $1 \mathrm{~h}$ at room temperature. After three washes with PBST, $100 \mu \mathrm{l}$ of serial two-fold dilutions of individual mouse sera in PBST were added and incubated at $37^{\circ} \mathrm{C}$ for $1 \mathrm{~h}$. The plates were washed three times with PBST, and $100 \mu \mathrm{l}$ of horseradish peroxidase-conjugate goat anti-mouse IgG (Amersham, Little Chalfont, Bucks, UK) 1:3000 diluted was added at $37^{\circ} \mathrm{C}$ for $1 \mathrm{~h}$. For subtyping of mouse antibodies, 1:50 dilution of pooled sera from each group was used. Biotinylated anti-mouse $\operatorname{IgG}$ of the appropriate subclass (Amersham, Little Chalfont, Bucks, UK) was added at 1:1000 dilution, followed by a streptavidin-biotinylated horseradish peroxidase conjugated (Amersham, Little Chalfont, Bucks, UK) diluted 1:3000 and incubated for $30 \mathrm{~min}$ at $37^{\circ} \mathrm{C}$. Posi- tive reactions were visualized with o-phenylenediamine (Sigma, St Louis, USA) in $0.1 \mathrm{M}$ citric acid, $0.2 \mathrm{M}, \mathrm{NaH}_{2} \mathrm{PO}_{4}$, $\mathrm{pH} 5.0$ and $0.015 \% \mathrm{H}_{2} \mathrm{O}_{2}$ as substrate; the reaction was stopped with $50 \mu \mathrm{l}$ of $2.5 \mathrm{M}, \mathrm{H}_{2} \mathrm{SO}_{4}$. Measurement of optical density (OD) at $492 \mathrm{~nm}$ was made in a plate reader (Merck, Darmstadt, Germany).

The cut-off value to consider a positive mouse anticore antibody response was established as twice the mean absorbance of the pre-immune sera.

To determine if human anti-HCV positive sera were able to bind to Co. 120 protein, a similar ELISA was carried out. Human sera were individually evaluated at 1:10 dilution in PBST. Anti-human IgG-peroxidase conjugate (Amersham, Little Chalfont, UK), diluted 1:3000, was employed instead of anti mouse IgG-peroxidase conjugate. The other steps were performed as described above. The cut-off value employed to consider a positive human anti-core antibody response was established as twice the mean absorbance of the negative control human sera.

The competition of antibodies from pIDKCo plasmidimmunized mice (PIM) with human anti-HCV positive sera for the binding to Co.120 protein was also studied by using essentially the same ELISA. After blocking, human sera at 1:10 dilution were added and incubated at $37^{\circ} \mathrm{C}$. One hour later, after three washes with PBST, the plates were incubated for $1 \mathrm{~h}$ at $37^{\circ} \mathrm{C}$ with pooled sera from each group of PIM at 1:50 dilution. Anti mouse IgG-peroxidase conjugate was also used at 1:3000 dilution. The inhibitory activity was expressed as percentage of inhibition and determined as follows:

Percentage of inhibition $=100 \times\left(\mathrm{A}_{492 \mathrm{~nm}}\right.$ of PIM Ab $\mathrm{A}_{492 \mathrm{~nm}}$ of PIM Ab bound to Co.120 in the presence of human anti-HCV positive sera)/ $\mathrm{A}_{492 \mathrm{~nm}}$ of PIM Ab).

Statistical analysis - To compare differences among groups, a One-way ANOVA with the Newman-Keuls post test was used. $P$ values $<0.05$ were considered significant.

\section{RESULTS}

Influence of additives in the anti-core antibody response-BALB/c mice were immunized with the pIDKCo plasmid alone or mixed with different additives. Animals were observed through 14 weeks for the development of anti-HCV core $\mathrm{Ab}$ response. Animals vaccinated with pAEC-K6 (control plasmid) did not show any reactivity against Co.120 protein when compared with their own preimmune sera. In contrast, five weeks after primary immunization, anti-core antibodies were detected in 80 and $100 \%$ of mice vaccinated with pIDKCo alone or mixed with the additives, respectively (data not shown).

The anti-capsid antibody response at week 5 and 14, determined as the $\mathrm{OD}_{492 \mathrm{~nm}} /$ cut-off ratio when the sera were diluted 1:50, is shown in Fig. 1A. The inclusion of $\mathrm{CaCl}_{2}$ in the immunogen did not improve the humoral immune response. On the other hand, the mixture of pIDKCo with PEG 6000, Freund's adjuvant and sCT-DNA induced a statistically stronger anti-core $\mathrm{Ab}$ response than immunization with pIDKCo alone $(\mathrm{p}<0.01)$ at week 5 of the schedule. However, at week 14 there were not differences in the anti-core antibody response among the groups of immunized mice.

Effect of different combinations of pIDKCo with Co.120 on anti-core antibody response - To investigate the effects of protein-DNA combinations on the anti-core $\mathrm{Ab}$ response, BALB/c mice were immunized with $\mathrm{pIDKCo}$ plasmid and Co. 120 protein in different formulations. Fig. 
1B shows the anti-core antibody response determined as $\mathrm{OD}_{492 \mathrm{~nm}}$ /cut-off ratio when the sera were diluted 1:50.

Five weeks after the primary immunization, all groups of immunized mice had anti-core antibodies except the group vaccinated with pAEC-K6. The combination of pIDKCo with Co.120 always produced a similar anti-core $\mathrm{Ab}$ response than the protein alone, and in both groups the anti-core antibody response was statistically higher than for the pIDKCo alone or the prime-boost schedules $(\mathrm{p}<0.05)$. There were no differences between the anti-core antibody responses induced by prime/boost schedules. However, five weeks after primary immunization, the priming with Co.120 and boost with pIDKCo rendered statistically higher response than the group immunized with pIDKCo alone $(\mathrm{p}<0.01)$.
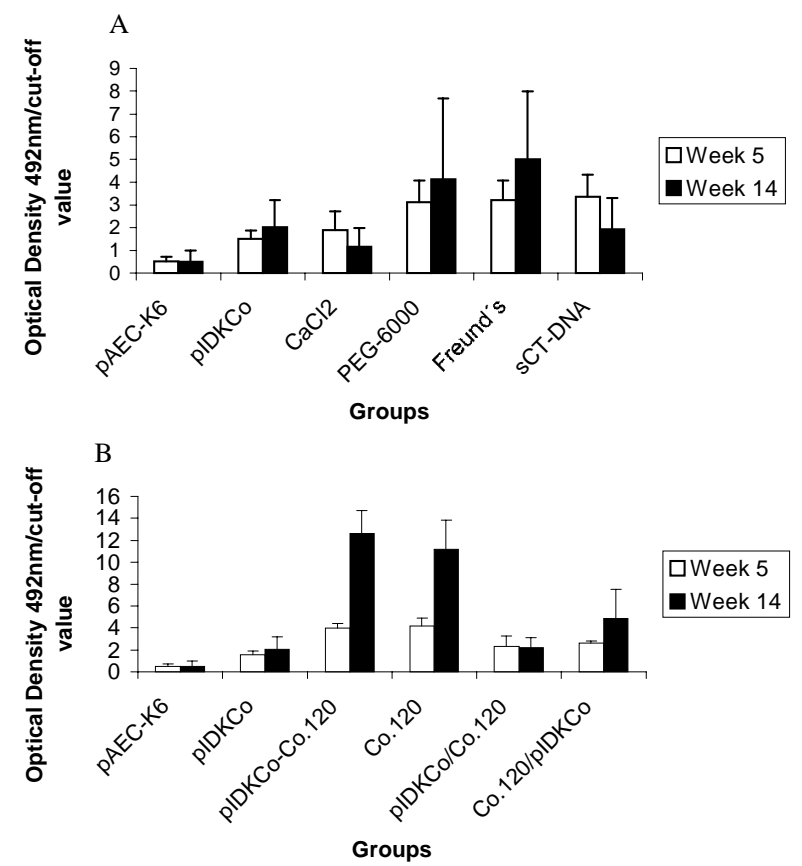

Fig. 1: effect of different additives (A) or pIDKCo and Co.120 combinations (B) on anti-core antibody response. Each $\mathrm{OD}_{492 \mathrm{~nm}}$ value was divided by the cutoff, and the bars represented the media of these values per group. The error bars represent the standard deviation of the mean.

Characterization of anti-core antibody elicited by the combination of plasmid with additives or protein - Sera from mice immunized with pIDKCo or Co.120 protein showed a mixed pattern of $\mathrm{IgG} 2 \mathrm{a} / \mathrm{IgG} 1$ anti-core antibodies. However, a tendency for predominance of IgG2a Abs was detected in the groups immunized with prime/boost schedules or pIDKCo-PEG 6000 and sCT-DNA combinations (Fig. 2A-B).

Furthermore, in order to characterize the specificity of anti-core $\mathrm{Ab}$ response in mice, an inhibition of binding ELISA was carried out (Table). Human sera were incubated with Co.120 protein before incubation of mouse sera with this recombinant protein. Results corresponding to sera from mice immunized with the mixture of pIDKCo with $\mathrm{CaCl}_{2}$ were not analyzed because both positive and negative anti-HCV human sera completely abolished the weak reactivity of these mouse sera to the Co.120 protein. Positive anti-HCV human sera maximally inhibited the binding of
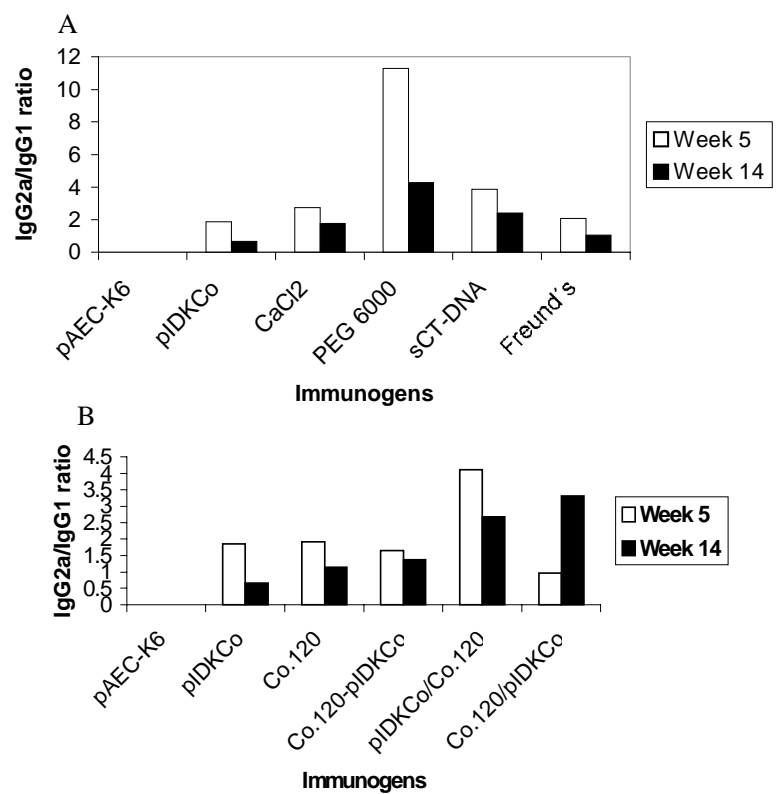

Fig. 2-A: measurement by ELISA of core-specific IgG1 and IgG2a subclasses elicited in BALB/c mice by injection with pIDKCo plasmid and additives. The media value of each determination was divided by the cutoff value; $B$ : measurement by ELISA of corespecific IgG1 and IgG2a subclasses elicited in BALB/c mice by injection with pIDKCo plasmid and Co.120 protein in different combinations.

anti-core $\mathrm{Ab}$ induced by pIDKCo alone. Interestingly, our results showed that the inclusion of additives and the combinations of plasmid with protein changed the epitope specificity of anti-core antibodies.

\section{DISCUSSION}

DNA-based immunization appears promising as a new way to administer vaccines. Such a vaccination strategy offers a means of mimicking important characteristics of live attenuated viral vaccines like the synthesis of native antigens and the induction of class I major histocompatibility complex-restricted cytotoxic T lymphocyte responses. However, nucleic acid vaccines do not seem to induce a response as strong as do conventional (lived attenuated) vaccines and consequently different approaches have been used to modulate the plasmid DNA immune responses. These efforts have been directed mainly to recruit immune cells and to facilitate the entry of plasmid DNA to cells.

Previous studies have shown that the intramuscular injection of plasmid expressing the HCV core protein was capable of inducing detectable core-specific antibody response, lymphoproliferative responses and cytotoxic Tlymphocyte activity in mice (Major et al. 1995).

In earlier attempts several doses of 100-200 $\mu \mathrm{g}$ of HCV core-encoding constructs have been generally administered in mice every second week. Nevertheless, only weak humoral immune responses have been induced against non-fused core variants by this way (Lagging et al. 1995, Chen et al 1995, Hu et al. 1999). In contrast, we have previously demonstrated that the pIDKCo plasmid induced a potent immune response following a DNA immunization schedule of five doses with increasing intervals between them (Dueñas-Carrera et al. 2000). 
TABLE

Inhibition of plasmid-immunized mice (PIM) polyclonal Antibodies binding to Co.120 protein by human anti-HCV positive sera 14 weeks after primary immunization

\begin{tabular}{|c|c|c|c|c|c|c|c|c|c|}
\hline Serum & $\begin{array}{c}\text { Co. } 120 \\
\text { reactivity }\end{array}$ & Co. 120 & $\begin{array}{c}\text { pIDKCo- } \\
\text { Co. } 120\end{array}$ & pIDKCo & PEG 6000 & Freund's & $\begin{array}{l}\text { sCT- } \\
\text { DNA }\end{array}$ & $\begin{array}{c}\text { pIDKCo/ } \\
\text { Co.120 }\end{array}$ & $\begin{array}{l}\text { Co.120/ } \\
\text { pIDKCo }\end{array}$ \\
\hline 1 & 4.3 & - & - & +++ & +++ & +++ & +++ & +++ & +++ \\
\hline 2 & 8.3 & $+/-$ & $+/-$ & +++ & +++ & + & - & + & - \\
\hline 3 & 6.4 & - & - & +++ & +++ & ++ & - & $+/-$ & - \\
\hline 4 & 8.2 & - & - & +++ & +++ & - & - & - & - \\
\hline 5 & 5.7 & ++ & ++ & +++ & +++ & +++ & +++ & +++ & + \\
\hline 6 & 3.5 & $+/-$ & $+/-$ & +++ & +++ & ++ & - & ++ & - \\
\hline 7 & 7.2 & + & $+/-$ & +++ & ++ & + & - & $+/-$ & - \\
\hline 8 & 6 & - & ++ & +++ & - & - & - & - & - \\
\hline 9 & 8 & - & - & +++ & - & + & - & + & - \\
\hline 10 & 6 & - & - & +++ & - & + & - & ++ & - \\
\hline 11 & - & - & - & - & - & - & - & - & - \\
\hline
\end{tabular}

The inhibition was analyzed by ELISA as described in Materials and Methods and presented as < $15 \%(-), 15$ to $30 \%(+/-), 30$ to $50 \%$ $(+), 50$ to $70 \%(++), 70$ to $100 \%(+++)$ inhibition. Percent inhibition $=100 \times\left(\mathrm{A}_{492 \mathrm{~nm}}\right.$ of PIM Ab $-\mathrm{A}_{492 \mathrm{~nm}}$ of PIM Ab bound to Co.120 in presence of human anti-HCV positive sera)/A $\mathrm{A}_{492 \mathrm{~nm}}$ of PIM Ab). Serum 11 is an anti-HCV negative serum. Reactivity against Co.120 is represented as times over the cutoff value and analyzed by ELISA as described in Materials and Methods.

PEG has been used to increase the efficiency of yeast transfection (Beggs 1978). Besides, this molecule has been used in combination with cationic lipids to increase DNA transfection in mammalian cells (Harvie et al. 2000). In fact, immunization with the combination of pIDKCo and PEG 6000 produced a temporary augment of the anti-core antibody response. This mixture also induced a bias through IgG2a subtype, suggesting the activation of cellular branch of immune response. Transfection efficiency experiments are required to correlate these effects with an increased plasmid uptake in vivo.

Since one of the problems of DNA immunization is the degradation of plasmid by extracellular nucleases, a way to ensure cells transfection is to protect the DNA from these enzymes. With this purpose we employed the sonicated calf thymus DNA as a substrate competitor to diminish nuclease specific degradation of the plasmid vaccine. This is the first report in which sonicated calf thymus is employed with the idea of protecting plasmid DNA from nucleases in vivo. Actually, we can not say that this molecule succeeded in that function, but it certainly caused a transient increase in anti-core antibody response when was combined with the pIDKCo plasmid. Remarkably, Weiner et al. (1997) have demonstrated that calf thymus DNA, in contrast to prokaryotic DNA, does not have an intrinsic adjuvant effect.

On the other hand, calcium salts have been used by Wang et al. (2000) to increase antibody titers in a formulation of a DNA vaccine encoding hepatitis B surface antigen. However, mixture of $\mathrm{CaCl}_{2}$ with pIDKCo did not stimulate the anti-core antibody response.

Prime-boost strategies have also been evaluated to increase immune response to the $\mathrm{HCV}$ core antigen. Chen et al. (1995) demonstrated that a second inoculation with the protein encoded by the vaccination plasmid recruited lymphocyte clones primed by the first inoculation with DNA. In the present work, only the prime Co.120/boost pIDKCo schedule transiently increased the anti-core antibody response with respect to the generated after immunization with pIDKCo alone. Moreover, the Co.120 protein alone or combined with the plasmid pIDKCo induced higher anti-core antibody response than pIDKCo alone or boosted with protein and vice versa. These results are consistent with the immunogenic character demonstrated by Co.120 in mice and rabbits (Dueñas-Carrera et al. 1999, Alvarez-Obregón et al. 2001), in spite of controversial results regarding the immunogenicity of truncated nucleocapsid proteins in mice (Inchauspe et al. 1997, Harase et al. 1997).

We compared the epitope specificities of anti-core antibodies in PIM with those in HCV-immune sera by an inhibitory assay. The information obtained in this experiment denoted that the human $\mathrm{HCV}$-immune sera had antibodies that could bind to the same regions in the $\mathrm{HCV}$ capsid that were recognized by antibodies in mice immunized with plasmid DNA. The level of inhibitory activity was not related with the reactivity of anti-HCV positive human sera to the capture antigen.

Interestingly, sera from mice immunized with plasmid combined with additives or Co.120 protein showed different behavior in the inhibitory assay regarding those from mice immunized with pIDKCo alone. Sera from mice immunized with pIDKCo evidenced the greatest inhibitory activity, confirming that anti-core antibodies induced in mice by immunization with pIDKCo were similar to those in human sera with respect to the epitope specificity (DueñasCarrera et al. 2000).

The results presented here confirmed that vaccination with HCV-core derived DNA sequences could be an effective method to induce humoral response to HCV. Moreover, our data indicate that kinetics, magnitude and epitope specificity of the anti-HCV core humoral immune response generated following DNA immunization could be modified by formulation and prime/boost strategies.

\section{ACKNOWLEDGEMENTS}

To Dr Antonieta Herrera and Dr Alejandro Martin for critical and constructive reading of the manuscript.

\section{REFERENCES}

Alvarez-Obregon JC, Dueñas-Carrera S, Valenzuela C, Morales J 2001. A truncated HCV core protein elicits a potent immune response with a strong participation of cellular immunity components in mice. Vaccine 19: 3940-3946. 
Beggs JD 1978. Transformation of yeast by a replicating hybrid plasmid. Nature 275: 104-109.

Chen Z, Wang RY-H, Alter HJ, Shih JW-K 1995. Genetic immunization of mice with plasmid containing hepatitis $\mathrm{C}$ virus core protein-encoding DNA. Vaccine Res 4: 135-144.

Chow Y-H, Huang WL, Chi W-K, Chu Y-D, Tao M-H 1997. Improvement of hepatitis B virus DNA vaccines by plasmids co-expressing hepatitis B surface antigen and Interleukin2. J Virol 71: 169-178.

Donnelly JJ, Ulmer JB, Shiver JW, Liu MA 1997. DNA vaccines. Annu Rev Immunol 15: 617-648.

Dueñas-Carrera S, Alvarez-Lajonchere L, Alvarez-Obregón JC, Herrera A, Lorenzo LJ, Pichardo D, Morales J 2000. A truncated variant of the hepatitis $C$ virus core induces a slow but potent response in mice following DNA immunization. $\mathrm{Vac}$ cine 19: 992-997.

Dueñas-Carrera S, Morales J, Acosta-Rivero N, Lorenzo LJ, García C, Ramos T, Guerra I, Peña M 1999. Variable level expression of hepatitis $\mathrm{C}$ virus core protein in a prokaryotic system. Analysis of the humoral response in rabbit. Biotecnología Aplicada 16: 226-231.

Gregoriadis G, Saffie R, de Souza B 1997. Liposome mediated DNA vaccination. FEBS Lett 402: 107-110.

Harase I, Moriyama T, Kaneko T, Kita H, Nomura M, Suzuki G, Ohnishi H, Muto Y, Yasaki Y, Imawari M 1995. Immune response to hepatitis $\mathrm{C}$ virus core protein in mice. Immunol Cell Biol 73: 346-352.

Harvie P, Wong FM, Bally MB 2000. Use of poly (ethylene glycol)-lipid conjugates to regulate the surface attributes and transfection activity of lipid-DNA particles. J Pharm Sci 89: 652-663.

Hasan UA, Abai AM, Harper DR, Wren BW, Morrow WJW 1999. Nucleic acid immunization: Concepts and techniques associated with third generation vaccines. J Immunol Meth 229: 1-22.

Horn NA, Meek JA, Budahazi G, Marquet M 1995. Cancer gene therapy using plasmid DNA: purification of DNA for human clinical trials. H Gene Ther 6: 565-573.

Hu G-J, Wang RY-H, Han DS, Alter HJ, Shih WK 1999. Characterization of the humoral and cellular immune responses against hepatitis $\mathrm{C}$ virus core induced by DNA-based immunization. Vaccine 17: 3160-3170.
Inchauspe G, Vitvitski L, Major ME, Jung G, Spengler U, Maisonnas M, Trepo C 1997. Plasmid DNA expressing a secreted or a nonsecreted form of hepatitis $\mathrm{C}$ virus nucleocapsid: comparative studies of antibody and T-helper responses following genetic immunization. DNA and Cell Biol 16: 185-195.

Jackson P, Petrik J, Alexander GJM, Pearson G, Allain J-P 1997. Reactivity of synthetic peptides representing selected regions of hepatitis $\mathrm{C}$ virus core and envelope proteins with a panel of hepatitis $\mathrm{C}$ virus-seropositive human plasma. $\mathrm{JMed}$ Virol 51: 67-79.

Klinman DM, Yamschikov G, Ishigatsubo Y 1997. Contribution of CpG motifs to the immunogenicity of DNA vaccines. $J$ Immunol 158: 3635-3639.

Lagging LM, Meyer K, Hoft D, Houghton M, Belshe RB, Ray R 1995. Immune responses to plasmid DNA encoding the hepatitis C virus core protein. J Virol 69: 5859-5863.

Major ME, Vitvitski L, Mink MA, Schleef M, Whalen RG, Trepo C, Inchauspe G 1995. DNA-base immunization with chimeric vectors for the induction of immune responses against the hepatitis C virus nucleocapsid. J Virol 65: 5798-5805.

Okamoto H, Tsuda F, Machida A, Munekata E, Akahane Y, Sugai Y, Mashiko K, Mitsui T, Tanaka T, Miyakawa Y, Mayumi M 1992. Antibodies against synthetic oligopeptides deduced from the putative core gene for the diagnosis of hepatitis C virus infection. Hepatology 15: 180-186.

Sasaki S, Hamajima K, Fukushima J, Ihata A, Ishii N, Gorai I, Hirahara F, Mohri H, Okuda K 1998. Comparison of intranasal and intramuscular immunization against human immunodeficiency virus type I with a DNA monophosphoryl lipid A adjuvant vaccine. Infect Immun 66: 823-826.

Walker CM 1996. Cytotoxic T-lymphocyte responses to the hepatitis $\mathrm{C}$ virus in humans and chimpanzees. Virology 7 : 13-21.

Wang S, Liu X, Fisher K, Smith JG, Chen F, Tobery TW, Ulmer JB, Evans RK, Caulfield MJ 2000. Enhanced type I immune response to hepatitis B DNA vaccine by formulation with calcium-or aluminum phosphate. Vaccine 18: 1227-1235.

Weiner GJ, Liu HM, Wooldridge JE, Dahle CE, Krieg AM 1997. Immunostimulatory oligodeoxynucleotides containing the $\mathrm{CpG}$ motif effective as immune adjuvants in tumor antigen immunization. Proc Natl Acad Sci 94: 10833-10837. 
